\title{
Intra-articular methotrexate associated to lipid nanoemulsions: anti-inflammatory effect upon antigen-induced arthritis
}

This article was published in the following Dove Press journal:

International Journal of Nanomedicine

5 February 2013

Number of times this article has been viewed

\section{Suzana BV Mello' \\ Elaine R Tavares ${ }^{2}$ \\ Adriana Bulgarelli ${ }^{2}$ \\ Eloisa Bonfá' \\ Raul C Maranhão 2,3}

'Rheumatology Division, Faculdade de Medicina da Universidade de São Paulo, São Paulo, Brazil; ${ }^{2}$ Lipid Metabolism Laboratory, the Heart Institute (INCOR) of the Medical School Hospital, São Paulo, Brazil; ${ }^{3}$ Faculty of Pharmaceutical Sciences, University of São Paulo, São Paulo, Brazil
Correspondence: Raul C Maranhão Laboratório de Metabolismo de Lípides, Instituto do Coração - HCFMUSP, Av Dr Enéas de Carvalho Aguiar, 44, 05403-000, São Paulo SP, Brazil Tel +55 II3 069595 I Fax +55 II30695574 Email ramarans@usp.br
Objective: Commercial methotrexate formulations (MTX) have poor anti-inflammatory action for intra-articular treatment of rheumatoid arthritis. Our aim was to investigate whether an association between methotrexate and lipidic nanoemulsions (LDE) could improve MTX intra-articular action.

Methods: For its association to LDE, MTX was previously esterified with dodecyl bromide. LDE-MTX was prepared by high pressure homogenization. Antigen-induced arthritis (AIA) was achieved in rabbits sensitized with methylated bovine serum albumin, and the rabbits were subsequently intra-articularly injected with the antigen. Twenty-four hours after AIA induction, groups of four to nine rabbits were intra-articularly injected with increasing doses $(0.0625-0.5 \mu \mathrm{mol} / \mathrm{kg})$ of LDE-MTX, and were compared to treatment with $0.5 \mu \mathrm{mol} / \mathrm{kg}$ commercial MTX, LDE alone, and saline (controls). Synovial fluid was collected 48 hours after AIA induction for analysis of protein leakage and cell content. Synovial membranes were collected for histopathology. Uptake of LDE labeled with ${ }^{3} \mathrm{H}$-cholesteryl ether by the synovial tissue was also determined.

Results: Uptake of radioactive LDE by arthritic joints was 2.5 -fold greater than by normal joints. Treatment with intra-articular LDE-MTX elicited a clear dose response pattern by reducing the synovial leukocyte infiltrate $(P=0.004)$ and protein leakage $(P=0.032)$ when compared with arthritic non-treated joints. In contrast, the intra-articular injection of commercial MTX and LDE did not reduce leukocyte infiltrate or protein leakage. Toxicity to treatment was not observed in any of the animals.

Conclusion: The association between LDE and MTX presented a marked anti-inflammatory effect that was absent after intra-articular commercial MTX treatment. Therefore, the new formulation is a candidate for future clinical studies.

Keywords: nanoparticles, cholesterol, methotrexate, arthritis, antigen-induced arthritis

\section{Introduction}

Rheumatoid arthritis is an autoimmune disease in which inflammation of the cells lining the synovium produces pain, swelling, and progressive erosion of the synovial joints. Methotrexate (MTX), an antiproliferative and immunosuppressive agent, is the drug of choice in the treatment of the disease. ${ }^{1}$ MTX is a folic acid antagonist used alone or in association with other therapeutic agents; however, MTX has an extensive toxicity range, which is the main cause of therapy withdrawal. MTX treatment is discontinued in $8 \%-19 \%$ of patients due to adverse reactions that include gastrointestinal, hepatic, renal, pulmonary, and hematological disturbances, and may also affect the central nervous system. ${ }^{2}$ Overall, $26 \%$ of patients discontinued MTX treatment due to poor 
response, high toxicity, or both. Thus, in addition to the relatively high toxicity, variability, and unpredictability of the pharmacological action, there are also drawbacks to the use of MTX treatment for rheumatoid arthritis. ${ }^{3}$

The interindividual variation in both effective MTX dose level and in toxicity has been ascribed to genetic polymorphisms. ${ }^{3}$ These polymorphisms affect receptors related with the transport of MTX into the cell, such as the reduced folate receptor and membrane-associated folate receptors, as well as enzymes involved in folate metabolism such as 5,10-methylenetetrahydrofolate reductase and thymidylate synthase. ${ }^{4}$ Genetic polymorphisms affecting the folate metabolic pathway and MTX transporters modify the toxicity of the drug, but do not seem to influence the efficacy of the drug. ${ }^{5}$ To circumvent the systemic toxicity of MTX, the use of the intra-articular route of drug administration was tested, but the results were not satisfactory because MTX is rapidly cleared from the joint cavity. ${ }^{6}$

In previous studies, we showed that nanoemulsions (LDE) that resemble the lipid structure of low-density lipoprotein (LDL) have the ability to concentrate in tissues undergoing proliferating processes, such as in malignant neoplasias or atherosclerotic lesions. ${ }^{7,8}$ LDE binds to LDL receptors, which are upregulated in those tissues, and this is the mechanism that favors the uptake and intracellular concentration of LDE via the receptor-mediated endocytosis pathway. When antiproliferative agents, such as paclitaxel, carmustine, or etoposide were associated with LDE, they promoted inhibition of tumor growth in murine oncologic models and they also inhibited the development of atheromatous lesions in rabbits with induced atherosclerosis. ${ }^{9-13}$ Association with LDE resulted in a remarkable reduction of the toxicity of those drugs.

In a recent study, we described a novel formulation consisting of an MTX derivative, di-dodecyl-MTX, associated with LDE. LDE-MTX is stable and, compared to commercial MTX, showed superior cytotoxicity as tested in cultured leukemia cells. ${ }^{14}$ The aim of the current study is to evaluate the effect of intra-articularly injected LDE-MTX on the inflammatory process in a rabbit model of arthritis in comparison with treatment using commercial MTX also administered by this route.

\section{Methods}

\section{LDE preparation and association of MTX}

LDE-MTX was prepared from a lipid mixture composed of $100 \mathrm{mg}$ of cholesteryl oleate, $200 \mathrm{mg}$ of egg phosphatidylcholine (Lipoid GMBH, Ludwigshafen, Germany), $10 \mathrm{mg}$ of triglycerides, $12 \mathrm{mg}$ of cholesterol, and $60 \mathrm{mg}$ of MTX. ${ }^{14-16}$ The aqueous phase consisting of $100 \mathrm{mg}$ of polysorbate 80 Tween 80 (Merk, Hohenbrum, Germany) and $10 \mathrm{~mL}$ of Tris$\mathrm{HCl}$ buffer $\mathrm{pH} 8.05$ was kept at room temperature. The preemulsion was obtained by adding the hydrophilic phase to the oil phase by ultrasonic radiation until complete dissolution of the drug. Emulsification of all lipids, MTX, and the aqueous phase was obtained by high-pressure homogenization using an Emulsiflex C5 homogenizer (Avestin Inc, Ottawa, Canada). After 30-40 minutes of homogenization at a constant temperature, the nanoemulsion was centrifuged at $1800 \times \mathrm{g}$ for 15 minutes to separate the emulsified and unbound MTX that precipitates upon centrifugation. The nanoemulsion was sterilized by passage through a $0.22 \mu \mathrm{m}$ pore polycarbonate filter (EMD Millipore Corporation, Billerica, MA, USA) and kept at $4^{\circ} \mathrm{C}$ until it was used. The incorporation of MTX to LDE was measured before its injection into animals by highperformance liquid chromatography. Prepared as described, the average diameter of the LDE-MTX particle was $60 \mathrm{~nm}$, as measured by Laser Light Scattering method performed using the ZetaPALS Zeta Potential Analyzer (Brookhaven Instruments Corporation, Holtsville, NY, USA).

\section{LDE uptake by the joint}

LDE at a $100 \mu \mathrm{L}$ volume labeled with $\left[{ }^{14} \mathrm{C}\right]$-cholesteryl ether (PerkinElmer Inc, Boston, MA, USA) was injected intravenously into the ear vein of three rabbits. Animals were kept in individual cages for 24 hours, when they were sacrificed. Fragments of synovial tissue were excised and kept in cold saline solution prior to lipid extraction with chloroform/ methanol $(2: 1 \mathrm{v} / \mathrm{v}) .{ }^{17}$ After lipid extraction, the solvent was evaporated under $\mathrm{N}_{2}$ flow and resuspended with $500 \mu \mathrm{L}$ of chloroform/methanol $(2: 1 \mathrm{v} / \mathrm{v})$, and half of the suspension was placed separately into vials with $5 \mathrm{~mL}$ scintillation solution (PerkinElmer, Inc., Boston, MA, USA), and the radioactivity was measured with a Packard 1600 TR liquid scintillation spectrometer (Packard BioScience, Inc, Palo Alto, CA, USA).

\section{Arthritis induction}

The Animal Ethics Committee of COBEA (Brazilian College of Experimental Animals) approved all experimental procedures performed on animals in accordance with The Universities Federation for Animals Welfare. Antigen-induced arthritis (AIA) was induced in New Zealand White rabbits. Animals were sensitized with $5 \mathrm{mg}$ of methylated bovine serum albumin (mBSA, Sigma-Aldrich Co, St Louis, MO, USA) in $1 \mathrm{~mL}$ of Freund's complete adjuvant 
(Gibco $^{\circledR}$; Life Technologies Corporation, Carlsbad, CA, USA) and $1 \mathrm{~mL}$ of sterile saline in multiple injections at subcutaneous and muscular sites in the supra-escapular and gluteal region, respectively. Fourteen days after immunization, the animals were boosted with five intradermical injections of $1 \mathrm{mg} / \mathrm{mL}$ of mBSA, and the onset of Arthus reaction with central necrosis was observed 24 hours later.

The animals used were those which appropriately responded to the cutaneous challenge. Arthritis was induced in the knee joint by injection of $0.5 \mathrm{~mL}$ of a sterile solution of mBSA ( $2 \mathrm{mg} / \mathrm{mL})$ into the intra-articular cavity. The contralateral joint was injected with saline. Forty-eight hours after the intra-articular challenge, the animal was sacrificed by an overdose of a mixture of xylazine $15 \mathrm{mg} / \mathrm{kg}$ (Bayer AG, São Paolo, Brazil) with ketamine 150 mg/kg (Parke Davis; Pfizer Inc, São Paolo, Brazil).

\section{Intra-articular injections of LDE-MTX, LDE, and commercial MTX}

Twenty-four hours after arthritis induction, animals were allocated into seven groups: one group was intra-articularly injected with a single dose of saline solution $(300 \mu \mathrm{L}, \mathrm{n}=9)$; the other four groups were intra-articularly injected with LDE-MTX at decreasing doses of $0.0625(n=4), 0.125$ $(\mathrm{n}=4), 0.25(\mathrm{n}=4)$, and $0.5 \mu \mathrm{mol} / \mathrm{kg}(\mathrm{n}=8)$; the last group was intra-articularly injected with a single dose of commercial $\operatorname{MTX}(0.5 \mu \mathrm{mol} / \mathrm{kg}, \mathrm{n}=4)$ and LDE alone $(300 \mu \mathrm{L}, \mathrm{n}=4)$.

\section{Synovial fluid sampling}

Immediately after sacrifice, $2 \mathrm{~mL}$ of saline containing ethylenediaminetetraacetic acid $(1 \mathrm{mg} / \mathrm{mL})$ were injected into each knee joint. Synovial fluid was collected with a needle, and the joint was then opened to recover the remaining fluid. The collected synovial fluid was diluted, and the total cell count was performed by light microscopy. The differential cell count was performed in smears prepared from cell pellet and stained by Giemsa.

\section{Assessment of vascular permeability}

Before the induction of arthritis, the animals were injected intravenously with $20 \mathrm{mg} / \mathrm{kg}$ of Evans Blue (INLAB, São Paulo, Brazil) in a $2.5 \%$ saline solution. The dye binds to plasma proteins originating within a tagged macromolecule that crosses the endothelial barrier only when tissues are inflamed. The joint fluid was centrifuged and the optical density was assessed by a colorimetric method at $630 \mathrm{~nm}$. The dye concentration in the joint was estimated from a standard curve of a weighed sample of Evans Blue serial dilutions in saline solution. Results are expressed as $\mu \mathrm{g}$ of protein $/ \mathrm{mL}$ of synovial fluid.

\section{Synovial membrane infiltrate}

Synovial membrane sections $(5 \mu \mathrm{m})$ were stained with hematoxylin and eosin for the quantification of cell infiltrate under light microscopy. The histological analysis was performed using at a $400 \times$ magnification in the microscope (BX-51; Olympus America Inc, Center Valley, PA, USA) fitted with a camera (Q Color 5; Olympus America Inc). Micrographs were processed using Image ProPlus software (version 6.0; Media Cybernetics Inc, Bethesda, MD, USA). Infiltrating leukocytes were assessed in five distinct digitalized panels per tissue fragment with a minimum of approximately $100 \mu \mathrm{m}^{2}$. The final result was expressed as the mean of infiltrated cells $/ 100 \mu \mathrm{m}^{2}{ }^{18,19}$

\section{Cytokines in synovial fluid}

Six cytokines (IL-1 $\beta$, IL-6, IL-10, IL-17, and tumor necrosis factor- $\alpha$ ) were measured simultaneously in the synovial wash samples using a microsphere-based multiplex immunoassay kit (EMD Millipore Corporation, Billerica, MA, USA) according to the manufacturer's instructions, using the saline, LDE, commercial MTX, and LDE-MTX $(0.5 \mu \mathrm{mol} / \mathrm{kg})$ experimental groups consisting of four rabbits.

\section{Statistics}

Results are expressed as means \pm standard error. The data have been subjected to repeated analysis of variance. Post hoc analysis was conducted using the Kruskal-Wallis multiple comparison tests. In all analyses, $P<0.05$ was considered statistically significant.

\section{Results LDE uptake by the joint}

As analyzed in three AIA rabbits injected with radioactive LDE, the amount of the nanoemulsion ${ }^{3} \mathrm{H}$-cholesterol oleate ether label found in the synovial membrane of the arthritic joints was roughly 2.5 times that found in the control, salineinjected joint.

\section{Leukocytes count in synovial fluid}

As shown in Figure 1, treatment of the AIA animals with intra-articular injection of commercial MTX at a $0.5 \mu \mathrm{mol} / \mathrm{kg}$ dose had no effect on the total leukocyte count in the synovial fluid as compared with the controls $\left(16,313 \pm 1947\right.$ cells $/ \mathrm{mm}^{3}$ versus $13,346 \pm 1144$ cells $\left./ \mathrm{mm}^{3}, P=0.154\right)$. It is important to note that, when compared with AIA, LDE alone did not 


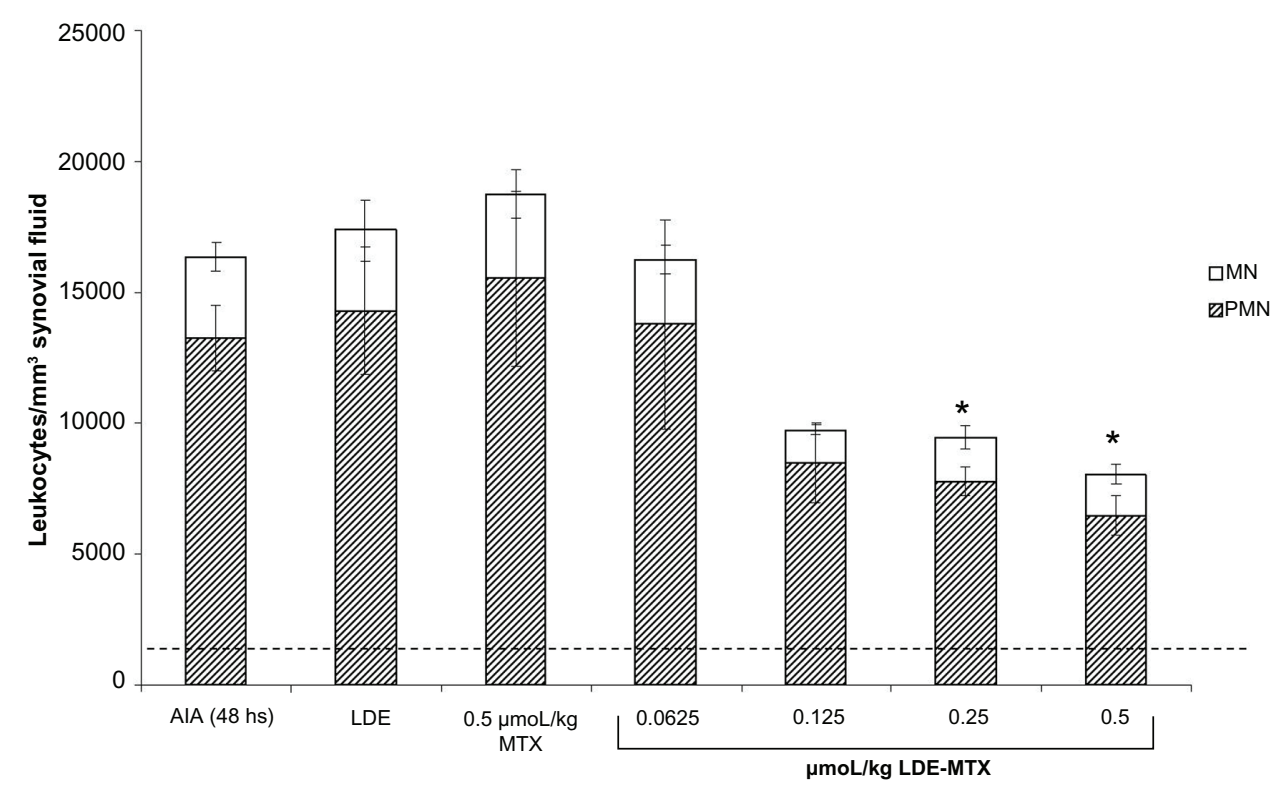

Figure I Leukocyte counts in the synovial fluid wash.

Notes: White bars indicate monocytes (MN); hatched bars indicate polymorphonuclear cells (PMN). Groups of four to nine animals were intra-articularly injected with saline, LDE alone, commercial MTX $(0.5 \mu \mathrm{mol} / \mathrm{kg})$, or LDE-MTX $(0.0625-0.5 \mu \mathrm{mol} / \mathrm{kg}), 24$ hours after AIA induction. The dotted line represents cells in the contralateral joints, in which arthritis was not induced. $* P<0.05$ compared to AIA.

Abbreviations: LDE, lipidic nanoemulsions; MTX, methotrexate; AIA, antigen-induced arthritis.

promote any alteration in the cellular influx of the joint $\left(17,375 \pm 1645\right.$ cells $\left./ \mathrm{mm}^{3}\right)$. In contrast, when the animals were treated with the intra-articular injection of LDE-MTX at the equivalent MTX dose $(0.5 \mu \mathrm{mol} / \mathrm{kg})$, there was a significant reduction in the total number of leukocytes in the synovial fluid $\left(8416 \pm 997\right.$ versus $13,346 \pm 1144$ cells $/ \mathrm{mm}^{3}$, $P=0.004)$. In Figure 1 , it is also shown that LDE-MTX had an apparent dose response curve, so that the lower LDE-MTX doses elicited lower reductions in the leukocyte count in the synovial fluid. However, only leukocyte count reductions produced by 0.5 and $0.25 \mathrm{MTX} \mu \mathrm{mol} / \mathrm{kg}$ dose levels were found to be statistically significant when compared to the controls. Regarding the differential count (Figure 1), a preferential population of cells affected by LDE-MTX injection was not found, so it seemed as though both mononuclear and polymorphonuclear cell counts were equally reduced by this treatment.

\section{Synovial membrane infiltrate}

Microscopic analysis of the synovial membrane of rabbits with 48 hours AIA that were intra-articularly treated with LDE-MTX is summarized in Figure 2. Figure 2A shows a low number of infiltrated leukocytes $\left(0.41 \pm 0.01\right.$ cells $\left./ 100 \mu \mathrm{m}^{2}\right)$ observed in the synovial membrane of a joint without arthritis. In Figure 2B, there is high leukocyte infiltration observed in the 48th hour of AIA in the untreated animals $\left(23.46 \pm 2.6\right.$ cells $\left./ 100 \mu \mathrm{m}^{2}\right)$. The efficacy of intra-articular treatment with LDE-MTX $(0.5 \mu \mathrm{mol} / \mathrm{kg})$ is shown in Figure $2 \mathrm{C}\left(2.96 \pm 0.44\right.$ cells $\left./ 100 \mu \mathrm{m}^{2}, P<0.0001\right)$. The leukocyte infiltrate in this tissue was very similar to those extracted from the joint without arthritis. In Figure 2D and $\mathrm{E}$, it is clear that the intra-articular injection of

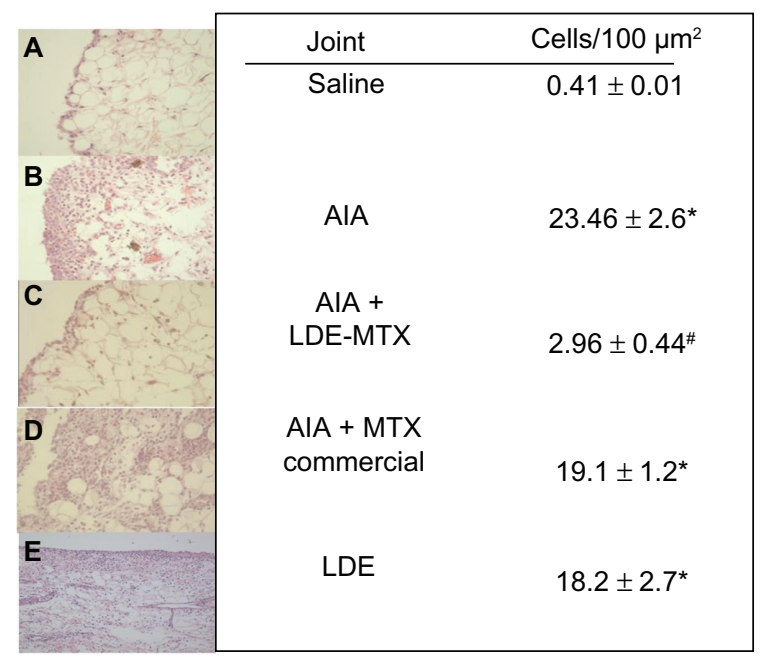

Figure 2 Typical micrographs of cell infiltrates in synovial membranes of the knee joints of rabbits. (A) Without arthritis; (B) with arthritis induced 48 hours beforehand; (C) treated with LDE-MTX $(0.5 \mu \mathrm{mol} / \mathrm{kg})$; (D) treated with commercial MTX $(0.5 \mu \mathrm{mol} / \mathrm{kg})$; and (E) treated with LDE alone. Synovial membranes were stained with hematoxylin/eosin.

Notes: Magnification: $400 \times$. Data in the figures refer to the number of cells $/ 100 \mu \mathrm{m}^{2}$. Results are expressed as mean \pm SE. $* P<0.05$ versus joint without arthritis; ${ }^{*} P<0.000$ I versus AIA.

Abbreviations: SE, standard error; LDE, lipidic nanoemulsions; MTX, methotrexate; AIA, antigen-induced arthritis. 
commercial MTX or LDE did not alter the leukocyte infiltrate in the arthritic synovial membrane $(19.1 \pm 1.2$ and $18.2 \pm 2.7$ cells $/ 100 \mu \mathrm{m}^{2}$, respectively). The cell counting data analysis exhibited in Figure 2 fully confirms that intra-articular treatment using LDE-MTX was effective in reducing infiltrated cells, although commercial MTX and LDE alone had no effect.

\section{Synovial vascular permeability}

As shown in Figure 3, the intra-articular treatment with LDEMTX at a $0.5 \mu \mathrm{mol} / \mathrm{kg}$ dose had the ability to reduce the protein leakage to the synovial fluid collected from the arthritic joints $(3.36 \pm 0.66$ versus $5.31 \pm 0.59 \mu \mathrm{g}$ of protein $/ \mathrm{mL}$, $P=0.032)$. In contrast, treatment with an equivalent dose of commercial MTX or LDE alone had no significant effect on protein leakage $(4.54 \pm 0.36$ and $5.5 \pm 1.41 \mu \mathrm{g}$ of protein $/ \mathrm{mL}$, respectively versus AIA the difference was not significant $[P=0.221$, ANOVA test $])$.

\section{Cytokines in synovial fluids}

Compared to the rabbits with AIA $(n=4)$, animals treated with intra-articular LDE-MTX at a $0.5 \mu \mathrm{mol} / \mathrm{kg}$ dose $(\mathrm{n}=4)$ showed diminished levels of IL-17 in synovial fluid (AIA $263.2 \pm 65.6$; LDE-MTX $17.6 \pm 9.9 \mathrm{pg} / \mathrm{mL})$, although the values did not reach significant levels $(P=0.05)$. Interferon gamma levels were also reduced by LDE-MTX treatment, although the values did not reach significant levels $(P=0.05)$. Commercial MTX or LDE treatments did not alter the cytokine level in the arthritic joint. Regarding the determination of IL-1 $\beta$, IL-6, IL-10, and tumor necrosis factor- $\alpha$, levels of these cytokines were undetectable in the fluid samples. This was probably due to the excess dilution of the synovial fluid samples that were collected by washing the joint with saline solution.

\section{Discussion}

The LDE-MTX preparation, as administered by an intra-articular route, was clearly effective in reducing the afflux of inflammatory cells to the joint. In contrast, the commercial MTX preparation at the same dose and route of administration had no effect, confirming the findings from previous literature..$^{20}$

The intra-articular route frequently used to treat inflammatory processes of the joint has failed in regards to commercial MTX. This occurs because MTX is rapidly exited from the joint cavity, resulting in low drug concentration. ${ }^{21}$ An alternative intra-articular approach was tested in rats, in which MTX was complexed with hyaluronic acid; this was also not successful in treating the inflammation due to fast clearance from the joint cavity. ${ }^{22}$ Liposome technology was also attempted to preserve MTX efficacy when

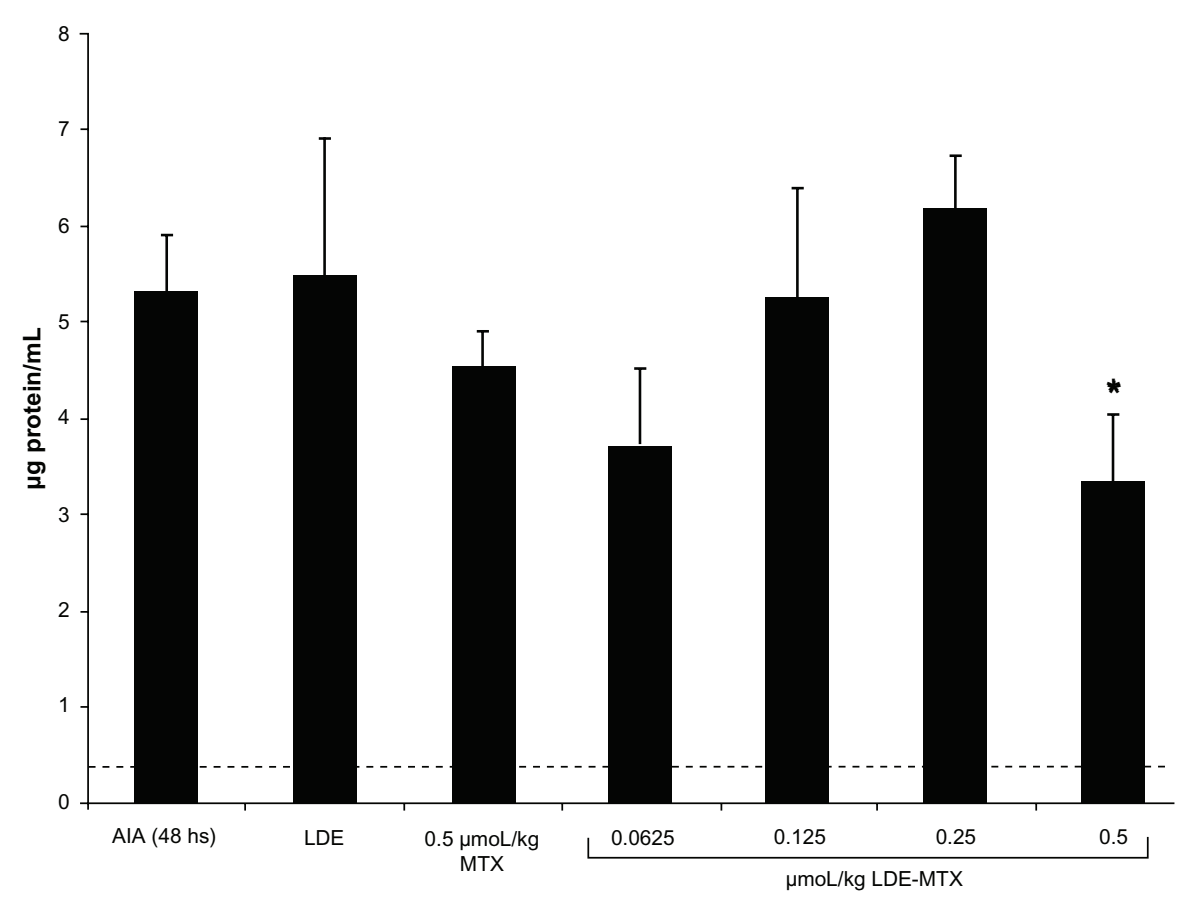

Figure 3 Vascular permeability assessed by Evans Blue method in the joint fluid collected from the articular cavity of rabbits 48 hours after arthritis induction. Notes: The animals (four to nine) were intra-articularly treated with LDE alone, MTX $(0.5 \mu \mathrm{mol} / \mathrm{kg})$, or LDE-MTX $(0.0625-0.5 \mu \mathrm{mol} / \mathrm{kg}) 24 \mathrm{hours}$ after arthritis induction. The AIA group was injected by the same route with sterile saline. The dotted line represents the protein leakage in the contralateral joint without arthritis. $* P<0.05$ versus $A$ IA. Abbreviations: LDE, lipidic nanoemulsions; MTX, methotrexate; AIA, antigen-induced arthritis. 
injected intra-articularly. The uptake by rabbit synovial tissues of MTX enveloped in liposome systems was low, but yet greater than MTX alone. Liposomal MTX also had a more intense therapeutic effect than MTX alone. ${ }^{20,21}$

Other studies performed in rats reported that liposomes with different composition and structure had different therapeutic effects due to the variations in intra-synovial retention time. ${ }^{23}$ Intra-articular liposomal MTX reduced pro-inflammatory interleukins, but only when injected on the same day of the arthritis induction. Apparently, none of the liposomal formulations had an effect on the established arthritis (ie, arthritis that was induced in the animals for more than $24 \mathrm{~h}$ ). Other MTX lipid-based carriers were also described in the literature for other therapeutic purposes; some examples include chylomicron-like emulsions being used as MTX carriers for cancer treatment, and emulsionassociated MTX for topical use in psoriasis treatment. ${ }^{24,25}$

LDL is removed from circulation by specific LDL or by lipoprotein-receptor related proteins, used as ligand apo B, which is the unique apo found in LDL. LDE, a stable nanoemulsion that resembles the lipid structure of native LDL, is made without apo B; however, in contact with plasma or other corporeal fluids, LDE acquires apo E from the other lipoproteins. ${ }^{26} \mathrm{Apo} \mathrm{E}$ is also an LDL-receptor ligand that has a much greater affinity for the receptor than apo B. Apo E is a ubiquitous protein found in body fluids and is present in substantial amounts in the joint fluid as secreted by synovial cells, and also by monocytes in inflamed joints. ${ }^{27}$ Therefore, when injected into the joint, LDE containing drug can pick-up apo $\mathrm{E}$ in the synovial fluid and is thus internalized into synovia cells by the LDL receptor endocytic pathway. In a previous study, we had shown that the intralesional injection of the nanoemulsion into breast carcinoma tissue resulted in a great concentration of LDE in the tumor. ${ }^{28}$ Likewise, the tropism of LDE for the inflamed synovial tissues was shown in the present experiment, whereby the injected radioactively labeled LDE was 2.5 times more concentrated in the arthritic joint than in the normal joint.

As we recently reported, LDL receptors offer a much more efficient internalization mechanism for MTX cell uptake than the folate receptors that internalize the commercial MTX formulation. ${ }^{14}$ We observed that the uptake of LDE-MTX by cultured neoplastic K562 and HL60 cells was considerably greater than that of commercial MTX. The greater uptake of LDE-MTX led to a much greater level of cytotoxicity than commercial MTX. Therefore, LDE use as a carrier offers an efficient mechanism through which to optimize MTX pharmacological action which, in the commercial preparation, is limited by poor cell uptake. ${ }^{14}$

The experimental model used in this study is advantageous insofar as it resembled human inflammatory arthritis in many respects, including the resulting synovitis. ${ }^{29}$ This increased uptake of LDE-MTX may account for the strong anti-inflammatory effect of this new complex, supported by the finding of a remarkable decrease in synovial cell infiltrates. Reinforcing this finding, a dose response curve was observed in the other two inflammatory parameters that were evaluated.

With respect to the effect of the different treatments on the cytokines present in the synovial fluid, it is remarkable that LDE-MTX, and not MTX alone, had the ability to diminish the cytokine levels, a finding that fully corroborates the antiinflammatory actions on cell counts in both synovial fluid and across the synovial membrane.

The single dose of $0.5 \mu \mathrm{mol} / \mathrm{kg}$ of body weight injected into the animal joint was devoid of toxicity. Accordingly, in experiments in which LDE-MTX was intravenously injected into rabbits at a high, $4 \mathrm{mg} / \mathrm{kg}$ body weight/week dose, no hematological, renal, or hepatic toxicities, weight loss, or food intake diminution were observed during the one month treatment period. ${ }^{30}$

Drug delivery systems may improve the physicochemical properties as well as increase the bioavailability of the therapeutic drug used for treatment, while decreasing the toxicity level of existing agents. In a sense, the use of these systems makes room for the reformulation of existing drugs, which is often more cost-effective and faster than the development of new drugs. ${ }^{31}$ The results of the current study clearly confirm these assumptions by showing that a drug that is virtually inactive when injected into the joint 48 hours after arthritis induction was endowed with strong anti-inflammatory action in association with LDE. In conclusion, the intraarticular injection of LDE-MTX seems to be a promising drug delivery strategy for treating arthritis.

\section{Acknowledgments}

The authors are grateful to Maria Aurora Gomes da Silva and Maria de Fátima de Almeida for their skillful technical assistance. This study was supported by Fundação do Amparo à Pesquisa do Estado de São Paulo (FAPESP), São Paulo, SP, Brazil, Conselho Nacional de Ciência e Tecnologia (CNPq), and the Federico Foundation (EB).

\section{Disclosure}

The authors report no conflicts of interest in this work. 


\section{References}

1. Suarez-Almazor ME, Belseck E, Shea B, Wells G, Tugwell P. Methotrexate for rheumatoid arthritis. Cochrane Database Syst Rev. 2000;2:CD000957.

2. Varatharajan N, Lim IG, Anandacoomarasamy A, et al. Methotrexate: long-term safety and efficacy in an Australian consultant rheumatology practice. Intern Med J. 2009;39(4):228-236.

3. Dervieux T, Furst D, Lein DO, et al. Polyglutamation of methotrexate with common polymorphisms in reduced folate carrier, aminoimidazole carboxamide ribonucleotide transformylase, and thymidylate synthase are associated with methotrexate effects in rheumatoid arthritis. Arthritis Rheum. 2004;50(9):2766-2774.

4. Ranganathan P, McLeod HL. Methotrexate pharmacogenetics: the first step towards individualized therapy in rheumatoid arthritis. Arthritis Rheum. 2006;54(5):1366-1377.

5. Braun J, Rau R. An update on methotrexate. Curr Opin Rheumatol. 2009;21(3):216-223.

6. Wigginton SM, Chu BC, Weisman MH, Howell SB. Methotrexate pharmacokinetics after intraarticular injection in patients with rheumatoid arthritis. Arthritis Rheum. 1980;23(1):119-122.

7. Ades A, Carvalho JP, Graziani SR, et al. Uptake of a cholesterolrich emulsion by neoplastic ovarian tissues. Gynecol Oncol. 2001; 82(1):84-87.

8. Padoveze AF, Maniero F, Oliveira TV, Vitorio TS, Couto RD, Maranhão RC. Effect of a cholesterol-rich diet on the metabolism of the free and esterified cholesterol components of a nanoemulsion that resembles LDL in rabbits. Braz J Med Biol Res. 2009;42(2):172-178.

9. Maranhão RC, Graziani SR, Yamaguchi N, et al. Association of carmustine with a lipid emulsion: in vitro, in vivo and preliminary studies in cancer patients. Cancer Chemother Pharmacol. 2002;49(6):487-498.

10. Rodrigues DG, Maria DA, Fernandes DC, et al. Improvement of paclitaxel therapeutic index by derivatization and association to a cholesterol-rich microemulsion: in vitro and in vivo studies. Cancer Chemother Pharmacol. 2005;55(6):565-576.

11. Lo Prete AC, Maria DA, Rodrigues DG, Valduga CJ, Ibañez OC, Maranhão RC. Evaluation in melanoma-bearing mice of an etoposide derivative associated to a cholesterol-rich nanoemulsion. J Pharm Pharmacol. 2006;58(6):801-808.

12. Maranhão RC, Tavares ER, Padoveze AF, Valduga CJ, Rodrigues DG, Pereira MD. Paclitaxel associated with cholesterol-rich nanoemulsions promotes atherosclerosis regression in the rabbit. Atherosclerosis. 2008;197(2):959-966.

13. Tavares ER, Freitas FR, Diament J, Maranhão RC. Reduction of atherosclerotic lesions in rabbits treated with etoposide associated with cholesterol-rich nanoemulsions. Int J Nanomedicine. 2011;6: 2297-2304.

14. Moura JA, Valduga CJ, Tavares ER, Kretzer IF, Maria DA, Maranhão RC. Novel formulation of a methotrexate derivative with a lipid nanoemulsion. Int J Nanomedicine. 2011;6:2285-2295.

15. Maranhão RC, Garicochea B, Silva EL, Llacer PD, Pileggi FJ, Chamone DA. Increased plasma removal of microemulsions resembling the lipid phase of low-density lipoproteins (LDL) in patients with acute myeloid leukemia: a possible new strategy for the treatment of the disease. Braz J Med Biol Res. 1992;25(10):1003-1007.
16. Maranhão RC, Garicochea B, Silva EL, et al. Plasma kinetics and biodistribution of a lipid emulsion resembling low-density lipoprotein in patients with acute leukemia. Cancer Res. 1994;54(17):4660-4666.

17. Folch J, Lees M, Sloane Stanley GH. A simple method for the isolation and purification of total lipids from animal tissues. J Biol Chem. 1957;226(1):497-509.

18. López-Armada MJ, Sánchez-Pernaute O, Largo R, et al. Modulation of cell recruitment by anti-inflammatory agents in antigen-induced arthritis. Ann Rheum Dis. 2002;61(11):1027-1030.

19. Pimentel TA, Sampaio AL, D’Acquisto F, Perretti M, Oliani SM. An essential role for mast cells as modulators of neutrophils influx in collagen-induced arthritis in the mouse. Lab Invest. 2011;91(1): 33-42.

20. Foong WC, Green KL. Treatment of antigen-induced arthritis in rabbits with liposome-entrapped methotrexate injected intra-articularly. J Pharm Pharmacol. 1993;45(3):204-209.

21. Foong WC, Green KL. Retention and distribution of liposome-entrapped $[3 \mathrm{H}]$ methotrexate injected into normal or arthritic rabbit joints. $J$ Pharm Pharmacol. 1988;40(7):464-468.

22. Homma A, Sato H, Okamachi A, et al. Novel hyaluronic acidmethotrexate conjugates for osteoarthritis treatment. Bioorg Med Chem. 2009; 17(13):4647-4656.

23. Williams AS, Topley N, Dojcinov S, Richards PJ, Williams BD. Amelioration of rat antigen-induced arthritis by liposomally conjugated methotrexate is accompanied by down-regulation of cytokine mRNA expression. Rheumatology. 2001;40(4):375-383.

24. Paliwal R, Paliwal SR, Mishra N, Mehta A, Vyas SP. Engineered chylomicron mimicking carrier emulsome for lymph targeted oral delivery of methotrexate. Int J Pharm. 2009;380(1-2):181-188.

25. Lin YK, Huang ZR, Zhuo RZ, Fang JY. Combination of calcipotriol and methotrexate in nanostructured lipid carriers for topical delivery. Int J Nanomedicine. 2010;5:117-128.

26. Almeida CP, Vital CG, Contente TC, Maria DA, Maranhão RC. Modification of composition of a nanoemulsion with different cholesteryl ester molecular species: effects on stability, peroxidation, and cell uptake. Int J Nanomedicine. 2010;5:679-686.

27. Terkeltaub RA, Dyer CA, Martin J, Curtiss LK. Apolipoprotein (apo) E inhibits the capacity of monosodium urate crystals to stimulate neutrophils. Characterization of intraarticular apo E and demonstration of apo E binding to urate crystals in vivo. J Clin Invest. 1991; 87(1):20-26.

28. Mendes S, Graziani SR, Vitório TS, et al. Uptake by breast carcinoma of a lipidic nanoemulsion after intralesional injection into the patients: a new strategy for neoadjuvant chemotherapy. Gynecol Oncol. 2009;112(2):400-404

29. Doria AS, Crawley A, Gahunia H, et al. Correlative BOLD MR imaging of stages of synovitis in a rabbit model of antigen-induced arthritis. Pediatr Radiol. 2012;42(1):63-75.

30. Bulgarelli A, Martins Dias AA, Caramelli B, Maranhão RC. Treatment with methotrexate inhibits atherogenesis in cholesterol-fed rabbits. J Cardiovasc Pharmacol. 2012;59(4):308-314.

31. Madani SY, Naderi N, Dissanayake O, Tan A, Seifalian AM. A new era of cancer treatment: carbon nanotubes as drug delivery tools. Int J Nanomedicine. 2011;6:2963-2979.

International Journal of Nanomedicine

\section{Publish your work in this journal}

The International Journal of Nanomedicine is an international, peerreviewed journal focusing on the application of nanotechnology in diagnostics, therapeutics, and drug delivery systems throughout the biomedical field. This journal is indexed on PubMed Central,

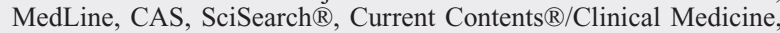

\section{Dovepress}

Journal Citation Reports/Science Edition, EMBase, Scopus and the Elsevier Bibliographic databases. The manuscript management system is completely online and includes a very quick and fair peer-review system, which is all easy to use. Visit http://www.dovepress.com/ testimonials.php to read real quotes from published authors. 